\title{
UMA ANÁLISE DOS PRINCIPAIS ELEMENTOS INFLUENCIADORES DA TOMADA DE DECISÃO DE COMPRA DE PRODUTOS DE MARCA PRÓPRIA DE SUPERMERCADOS
}

\author{
Lúcia Aparecida da Silva \\ luciaasilva@gmail.com \\ Universidade de São Paulo - Ribeirão Preto, SP / Brasil \\ Edgard Monforte Merlo \\ edgardmm@usp.br \\ Universidade de São Paulo - Ribeirão Preto, SP / Brasil \\ Marcelo Seido Nagano \\ drnagano@usp.br \\ Universidade de São Paulo - São Carlos, SP / Brasil
}

\begin{abstract}
Recebido em 16/02/2010
Aprovado em 30/06/2011

Disponibilizado em 01/04/2012

Avaliado pelo sistema double blind review

Revista Eletrônica de Administração

Editor: Luís Felipe Nascimento

ISSN 1413-2311 (versão on-line)

Editada pela Escola de Administração da Universidade Federal do Rio Grande do Sul.

Periodicidade: Quadrimestral
\end{abstract}

Sistema requerido: Adobe Acrobat Reader.

\section{RESUMO}

A adoção de marcas próprias no mix de produtos de supermercados é uma ação estratégica que alguns varejistas estão utilizando para melhorar sua competitividade no setor. No Brasil, a participação de mercado das marcas próprias ainda é pouco representativa, o que reflete a atitude dos consumidores diante desses produtos. A proposta deste trabalho foi avaliar os fatores que influenciam no comportamento do consumidor em relação aos produtos de marcas próprias de supermercados. Foi desenvolvida uma pesquisa de campo de caráter exploratório com abordagem quantitativa, por meio de questionário auto-administrado, o que possibilitou a coleta de opiniões de uma amostra de 983 clientes de supermercados. Os resultados obtidos demonstram que os respondentes não possuem uma imagem positiva dos produtos de marcas próprias, devido: à grande variação na qualidade dos produtos dentro das categorias e entre as categorias ofertadas, ao risco percebido, à ausência de comunicação efetiva sobre os produtos e à imagem de inferioridade transmitida pelos atributos das marcas próprias como embalagem, forma de exposição e política de preços. Dos fatores obtidos, pode-se concluir que a imagem da loja, a comunicação e preço, a qualidade e preço destacaram-se como os mais importantes para os respondentes e que exerceram maior influência em seu comportamento.

Palavras-chave: varejo, marca própria de supermercado, comportamento do consumidor. 
Uma análise dos principais elementos influenciadores da tomada de decisão de compra de produtos de marca própria de supermercados

\title{
AN ANALYSIS OF THE KEY ELEMENTS INFLUENCING THE DECISION TO PURCHASE PRIVATE LABEL PRODUCTS IN SUPERMARKETS
}

\begin{abstract}
The adoption of own brands in the product mix of supermarkets is a strategic action that some retailers are using to improve their competitiveness in the sector. In Brazil, private labels market share is still under represented, which reflects the attitude of consumers relating to these products. The purpose of this study was to evaluate the factors that influence the consumption of private label products in supermarkets. It was developed a field exploratory research, using self-administered questionnaire which allowed the collection of opinions of a sample of 983 supermarket shoppers. The results show that respondents don't have a positive image of private label products partially related to: great variation in quality of products within categories and between offered categories, the perceived risk, lack of effective communication about products and the image of inferiority transmitted by the attributes of brand labels such as packaging, merchandising method and price policy. Obtained factors show that the store image, communication and price, quality and price stood out as most important to respondents and that have the greatest influence on consumer behavior.
\end{abstract}

Keywords: retail, supermarket's private labels, consumer's behavior.

\section{UN ANÁLISIS DE LOS PRINCIPALES ELEMENTOS INFLUENCIADORES DE LA TOMADA DE DECISIÓN DE COMPRA DE PRODUCTOS DE MARCA PROPIA DE SUPERMERCADOS}

\begin{abstract}
RESUMEN
La aceptación de marcas propias en el mix de productos de supermercados es una acción estratégica que algunos compradores al por menor utilizan para mejorar la competencia en el sector. En Brasil, la participación de mercado de las marcas propias todavía es poco representativa, lo que refleja la actitud de los consumidores con respecto a estos productos. La propuesta de este estudio ha sido evaluar los factores que influyen en el comportamiento del consumidor en relación a los productos de marcas propias de supermercados. Se ha desarrollado una investigación de campo de carácter exploratorio con abordaje cuantitativo, por medio de cuestionario auto-administrado, lo que posibilitó la coleta de opiniones de una muestra de 983 clientes de supermercados. Los resultados obtenidos demuestran que los respondientes no poseen una imagen positiva de los productos de marcas propias, debido: a la gran variación en la calidad de los productos en las categorías y entre las categorías ofrecidas, al riesgo percibido, a la ausencia de comunicación efectiva sobre los productos y a la imagen de inferioridad transmitida por los atributos das marcas propias como envase, forma de exposición y política de precios. De los factores obtenidos, se puede concluir que la imagen de la tienda, la comunicación y precio, la calidad y precio se han destacado como los más importantes para los respondientes y que han ejercido mayor influencia en su comportamiento.
\end{abstract}

Palabras clave: compra al por menor, marca propia de supermercado, comportamiento del consumidor. 
Lúcia Aparecida da Silva, Edgard Monforte Merlo \& Marcelo Seido Nagano

\section{INTRODUÇÃO}

O setor varejista, devido à alta competitividade, vem passando por grandes transformações exigidas pela necessidade de rápida adequação ao mercado, a fim de atender de forma eficiente e eficaz às exigências do consumidor (PARENTE, 2000).

A criação e a adoção de estratégias para a permanência neste ambiente competitivo passam a ser um desafio para o setor. Dentre essas estratégias, a decisão sobre o sortimento de produtos a ser ofertado para o consumidor é importante e pode se tornar um fator determinante para o posicionamento da loja. Segundo Parente (2000), a definição do mix de produtos significa definir a composição da variedade que o ponto de venda irá oferecer, e dentro desta composição uma importante decisão refere-se às marcas que serão inseridas no mix de produtos.

A utilização de marcas próprias no varejo é um fenômeno que está ocorrendo em todo o mundo, entretanto no Brasil, sua utilização ainda está no início, representando 4,8\% de participação nas vendas em valor e 6\% em volume no país (NIELSEN, 2010). Porém, com a estabilidade econômica e a crescente concentração do varejo nas mãos de poucas redes, podese inferir que este crescimento é inevitável.

Nesse contexto, ganha importância para os gestores a necessidade do conhecimento do cliente, de suas preferências e dos motivadores na escolha das marcas. Engel, Blackwell e Miniard (2000) afirmam que entender e adaptar-se à motivação e ao comportamento do consumidor não é uma opção - é a necessidade absoluta para a sobrevivência competitiva. No que se refere à atitude, Wells e Prensky (1996) afirmam que as atitudes precedem e produzem o comportamento. Assim, o desafio é entender quais são os fatores que mais influenciam na atitude do consumidor frente aos produtos de marcas próprias.

Em relação a esse aspecto, Ailawadi Neslin e Gedenk, (2001); Shannon e Mandhachitara (2005); Vahie e Paswan (2006); Hidalgo et al. (2007) apresentam fatores que são determinantes na formação desta atitude e na propensão dos consumidores a comprarem marcas próprias, dentre eles: a imagem da loja, o risco percebido, a estratégia de comunicação do varejista, a qualidade dos produtos com marcas próprias, a estratégia de preços e a lealdade à loja.

Considerando todos estes aspectos mencionados, o presente artigo avaliou os fatores que exercem maior influência na decisão de compra dos produtos de marcas próprias de supermercados. Mesmo não fazendo parte do hábito de compra de muitos consumidores brasileiros, os produtos de marcas próprias têm merecido destaque pelos benefícios que proporcionam tanto para o varejista em termos de fidelização do cliente e melhores margens, 
Uma análise dos principais elementos influenciadores da tomada de decisão de compra de produtos de marca própria de supermercados

quanto para o consumidor no que se refere à melhor relação entre custo e benefício. Porém, da mesma forma que a adoção de marcas próprias no mix de produtos do supermercado proporciona vários benefícios ao supermercadista se for mal gerenciada pode trazer riscos.

A contribuição desse artigo está localizada na proposta de uma discussão acerca dos elementos que influenciam os consumidores na compra de produtos de marcas próprias e na identificação, dentre os elementos estudados, dos que exercem maior influência no comportamento de compra do consumidor.

Para o alcance do objetivo desse estudo, foi feita uma pesquisa de campo com abordagem quantitativa, por meio de uma survey com questionário auto-administrado junto a clientes de supermercados no Brasil. O instrumento de coleta de dados foi elaborado com base no modelo da Teoria da Ação Racional (TRA) de Fishbein e objetivou avaliar os principais elementos que influenciam na decisão de compras dos consumidores de marcas próprias.

Após a introdução, o trabalho apresenta e discute o referencial teórico com destaque à marcas próprias e seu desenvolvimento. Adicionalmente, é discutida a relação entre atitude e comportamento do consumidor e entre a atitude e marcas próprias. Em seguida, é apresentado o método de pesquisa adotado e as escolhas envolvidas na amostra, instrumento de coleta de dados e técnicas analíticas utilizadas. $\mathrm{Na}$ seção subsequente são apresentadas a análise e discussões dos resultados, e por fim, são apresentadas as considerações finais.

\section{REFERENCIAL TEÓRICO}

\subsection{Varejo}

Conforme Parente (2000) entende-se por varejo o conjunto de todas as atividades que englobam o processo de venda de produtos e serviços para atender a uma necessidade pessoal do consumidor final. Levy e Weitz (2000) complementam que esta atividade de negócio adiciona valor aos produtos e serviços que são vendidos aos consumidores para o uso tanto pessoal quanto familiar. Nesse sentido, a ênfase para o conhecimento dos hábitos, atitudes e padrões de comportamento dos consumidores no varejo segundo Souza e Serrentino (2002) é fundamental na construção de uma estratégia bem sucedida no setor.

No que se refere aos tipos de varejos no Brasil, segundo Parente (2000), os mais importantes são os hipermercados, supermercados, lojas de conveniência, lojas de especialidades e mercearias. Especificamente, com relação a supermercados, Saab e Gimenez (2000a) caracterizam este formato de varejo pela venda predominante de alimentos frescos, ou mercearias e artigos de higiene e limpeza, com alto giro e baixa margem por praticar preços competitivos, aplicam o conceito de auto-serviço e contemplam um mínimo de dois 
Lúcia Aparecida da Silva, Edgard Monforte Merlo \& Marcelo Seido Nagano

check outs e área de vendas superior a $350 \mathrm{~m}^{2}$, diferenciando do hipermercado que atua com área de vendas superior a $5.000 \mathrm{~m}^{2}$.

Borges (2001) ressalta que poucos foram os setores da economia brasileira que apresentaram um crescimento tão acelerado quanto o de supermercados, e que, em cinco décadas, essa evolução saiu da era do varejo de armazéns, empórios e feiras livres para a instalação de redes de lojas cobrindo todo o país. Porém, independente do tamanho da loja e do formato da mesma, pode-se inferir que cresce a importância do desenvolvimento de um composto mercadológico eficaz, capaz de proporcionar ao varejista o posicionamento desejado. Com esse crescimento aspectos como a estratégia de composto de marketing ganhou importância acentuada como ferramenta de competição.

As decisões estratégicas para o composto de marketing envolvem a criação de uma combinação de produto, preço, ponto e promoção que, na maior extensão possível, atenda às necessidades do mercado-alvo (FERREL, O. C. et al. 2000). O Erro! Fonte de referência não encontrada., ilustra as variáveis deste composto e algumas decisões que são tomadas para que o varejista consiga uma diferenciação no mercado em que atua.

Quadro 1. Composto Varejista - os 6P's

\begin{tabular}{|c|c|}
\hline Variáveis do composto varejista & Exemplo de decisões \\
\hline Mix de Produtos & Variedade da linha, Qualidade, Serviços, Marcas \\
\hline Preços & Preços, Crédito, Benefício/Custo. \\
\hline Promoção & Propaganda, Ofertas, Sinalização \\
\hline aPresentação & Loja, Departamentalização, Planograma \\
\hline Pessoal & Atendimento, Rapidez, Serviços \\
\hline Ponto & Localização, Acesso, Visibilidade. \\
\hline
\end{tabular}

Fonte: Parente (2000, p. 61)

A definição das marcas a serem ofertadas é uma decisão estratégica do mix de produtos. McGoldrick (2002) enfatiza o crescimento das marcas próprias no sortimento da loja e afirma que produtos com marcas próprias têm representado um papel importante no desenvolvimento de alguns varejistas, e que este fenômeno ilustra o aumento do poder varejista e da sofisticação do marketing.

\subsection{Marcas próprias}

Segundo Richardson, Dick e Jain (1994), os varejistas têm uma escolha a fazer: podem ser vistos como distribuidores passivos das marcas nacionais ou como ativos desenvolvedores 
Uma análise dos principais elementos influenciadores da tomada de decisão de compra de produtos de marca própria de supermercados

da marca de sua loja. Santos, Campomar e Toledo (2010) complementam que o tradicional papel de intermediário do canal de distribuição com a missão de facilitar a entrega do produto do fabricante ao consumidor final vem ampliando continuamente e se confundindo com o do próprio fabricante e fornecedor. Desta forma, as marcas próprias ou marcas de loja são produtos criados por um varejista e levam sua marca (LEVY; WEITZ, 2000).

Dick, Jain e Richardson (1997) sugerem que os gestores de marcas próprias se esforcem para estabelecer uma imagem de marca forte para suas linhas de produtos realizando investimentos em publicidade e promoções destinadas a familiarizar os consumidores com suas marcas próprias visando melhorar as expectativas proporcionadas pela marca.

Entretanto, Gracioso e Najjar (2003) afirmam que nem sempre a marca própria pode levar o mesmo nome da empresa varejista. No quadro a seguir são apresentadas as vantagens e desvantagens de cada uma destas opções baseando-se no ponto de vista destes autores.

Quadro 2. Tipos de classificação para marcas próprias

\begin{tabular}{|c|c|c|}
\hline \multicolumn{3}{|c|}{ Nome da empresa $x$ Marca diferente } \\
\hline & Mesmo nome & Outro nome \\
\hline Motivação & $\begin{array}{l}\text { Capitalizar o conhecimento da } \\
\text { marca e a credibilidade } \\
\text { reconhecida pelo mercado. }\end{array}$ & $\begin{array}{l}\text { Adaptarem-se ao mercado, } \\
\text { consolidando uma nova marca } \\
\text { exclusiva para cada categoria de } \\
\text { produto. }\end{array}$ \\
\hline Vantagens & $\begin{array}{l}\text { Utilização e fortalecimento da } \\
\text { imagem da marca, aumento de } \\
\text { vendas e lucro, especialmente se a } \\
\text { marca da loja for forte, divulgação } \\
\text { da empresa e fidelização dos } \\
\text { clientes. }\end{array}$ & $\begin{array}{l}\text { Preservação do nome da loja, não } \\
\text { vincula sua reputação à aceitação } \\
\text { do produto, oferece mais opções de } \\
\text { produtos, adequa melhor o nome } \\
\text { da marca a cada categoria de } \\
\text { produto, atende e satisfaz públicos } \\
\text { distintos }\end{array}$ \\
\hline Desvantagens & $\begin{array}{l}\text { Necessidade de maior controle da } \\
\text { qualidade dos produtos devido à } \\
\text { associação direta com o nome da } \\
\text { empresa. }\end{array}$ & $\begin{array}{l}\text { Exige mais trabalho para } \\
\text { gerenciamento de marcas, mais } \\
\text { oneroso e não há associação direta } \\
\text { com a loja }\end{array}$ \\
\hline Exemplo & Carrefour; Bompreço; Barateiro & Qualitá; Taeq; Great Value \\
\hline
\end{tabular}
Fonte: Adaptado de Gracioso e Najjar (2003)

McGoldrick (2002) ressalta que os varejistas que possuem uma imagem de alta qualidade enfrentam condições mais favoráveis para a introdução de marcas próprias, utilizando o nome da rede em diversas categorias de produto. A decisão de aplicar ou não a marca da rede nos produtos marca própria depende da imagem percebida pelos consumidores diante da empresa varejista.

Com relação ao sistema de desenvolvimento de marcas próprias, Monteiro Neto (2001) afirma que este deve envolver o estabelecimento claro do segmento-alvo; a definição 
das vantagens e benefícios da função dos produtos para os consumidores; a definição do produto e o seu composto; e a divulgação das vantagens para o consumidor.

No que se refere à diferenciação das marcas próprias, McGoldrick (2002) afirma que a maioria dos varejistas usa o preço como um importante atributo para obtenção de vantagem competitiva para os produtos com sua marca. Entretanto, como os fabricantes têm respondido ao desafio, pelo ajuste de suas despesas e margens, tem se tornado mais difícil conseguir uma diferenciação de sucesso por meio de preços baixos nos produtos de marcas próprias.

Neste sentido, pode-se observar no mercado, que há varejistas que desenvolvem produtos de marcas próprias que concorrem diretamente com as marcas-líderes, inclusive na faixa de preços que podem ser iguais ou um pouco menores, como a marca Qualitá do grupo Pão de Açúcar. E há aqueles varejistas que optam por preços baixos, agregando valor ao apresentarem preços competitivos.

Os varejistas podem obter alguns benefícios com o lançamento de marca própria; como o aumento da margem de lucro por meio de maior volume de vendas destes produtos; a construção da imagem varejista, pois esta estratégia é importante em termos de posicionamento; a racionalização das linhas de produtos, pois, podem-se eliminar linhas de marcas nacionais que são secundárias nas ofertas de produtos; aumentar o controle e melhoria de relacionamento com fornecedores (EUROMONITOR INTERNATIONAL, 1998).

Nota-se que é estratégica a adoção de marcas próprias no mix de produtos do supermercado, porém o varejista deve ficar atento às questões mercadológicas para inserção dessas linhas de produto no mercado, pois, da mesma forma que a adoção proporciona vários benefícios ao supermercadista, traz riscos caso a estratégia não seja implantada adequadamente.

\subsection{O desenvolvimento de marcas próprias}

Parente (2000) afirma que, no Brasil, a importância das marcas próprias é menor do que em outros países da Europa ou América do Norte. Segundo Nascimento (2005) as marcas próprias no Brasil tiveram início com os produtos genéricos no começo do século XX. Estes produtos não tinham nenhuma diferenciação e na embalagem era identificado apenas o produto. O principal diferencial era o preço, pois não oferecia valor agregado.

Segundo o autor, na década de 1970 que os varejistas começaram a estampar a marca de suas lojas nos produtos, criando linhas de produtos para competir com as tradicionais. Porém, de acordo com a Nielsen (COMPRO, 2007), apesar do elevado crescimento anual, a 
Uma análise dos principais elementos influenciadores da tomada de decisão de compra de produtos de marca própria de supermercados

participação desses produtos no mercado de consumo interno ainda está muito distante dos mercados de países europeus, como mostra a Erro! Fonte de referência não encontrada..

Figura 1. Participação das marcas próprias no mercado europeu

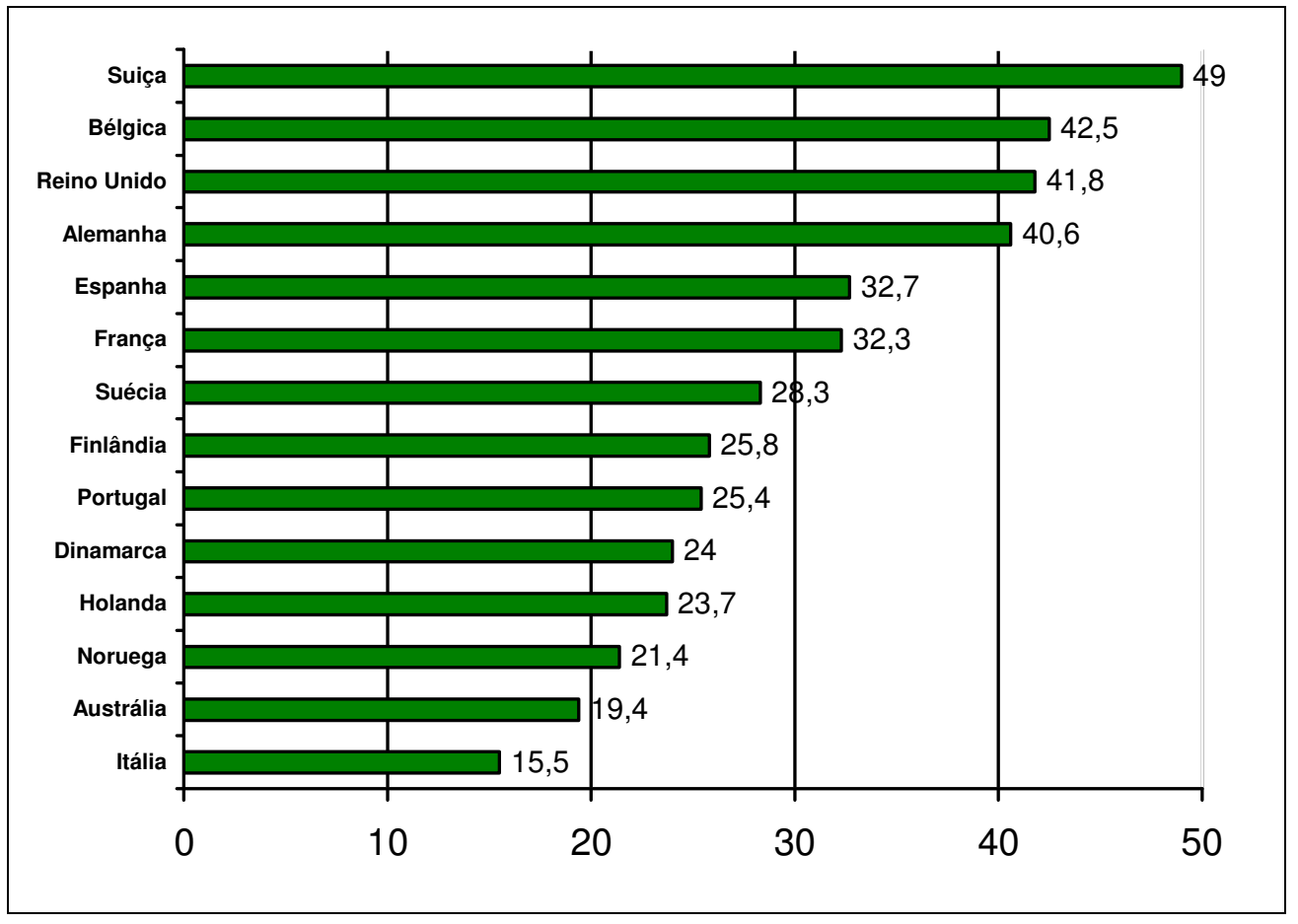

Fonte: COMPRO (2007, p. 20)

Percebe-se que há países na Europa em que a participação de marcas próprias está acima de $40 \%$. No Brasil, comparando a participação das marcas próprias com outros países, tanto do continente americano, como Canadá e Estados Unidos, quanto do continente europeu, nota-se que ainda há muito espaço para crescer.

A seguir é apresentada a evolução do faturamento de produtos de marca própria no varejo brasileiro. 


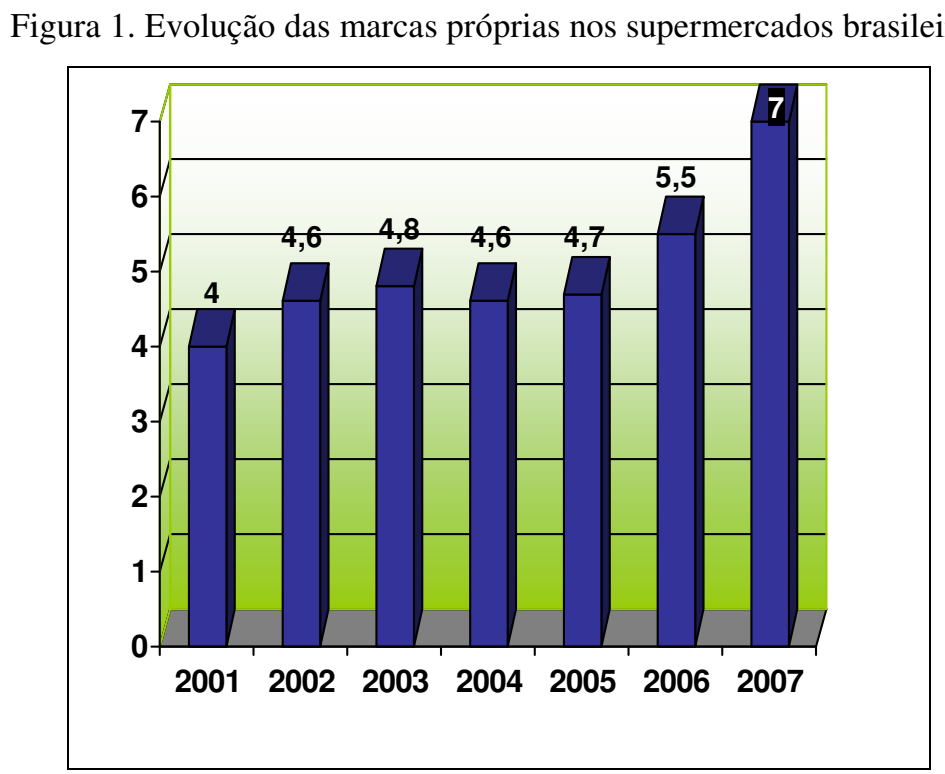

Fonte: Abras (2008, p. 92)

Verifica-se que, nos anos de 2001 a 2005, a participação das marcas próprias no mercado brasileiro manteve-se praticamente constante. Um relevante aumento ocorreu, principalmente, do ano de 2006 para 2007, aumentando de 5,5\% para 7\%, ou seja, um aumento de 27,3\% no período. Conforme a Abras (2008) este crescimento deveu-se a: adequação do mix às preferências dos clientes, implementação de mais serviços, aumento do número de lojas que abrem aos domingos, melhoria na operação de loja, desenvolvimento de ações institucionais, lançamento de novos produtos de marcas próprias. Porém, mesmo com este aumento, observa-se que os produtos de marcas próprias possuem baixa representatividade na participação de mercado no Brasil comparada com outros países do continente americano e europeu.

\subsection{Atitude e comportamento}

Segundo McGoldrick (2002), o fundamental para a formulação da estratégia de marketing no varejo é uma compreensão clara das necessidades do consumidor, dos motivos e do processo de decisão de compra, ou seja, é necessário conhecer o comportamento do consumidor. Para Engel, Blackwell e Miniard (2000, p. 4), “o comportamento do consumidor é definido como as atividades diretamente envolvidas em obter, consumir e dispor de produtos e serviços, incluindo os processos decisórios que antecedem e sucedem estas ações". Pode-se inferir que estudar o comportamento do consumidor auxilia no conhecimento das 
Uma análise dos principais elementos influenciadores da tomada de decisão de compra de produtos de marca própria de supermercados

preferências do consumidor, tendo em vista que este é um requisito fundamental para que as empresas consigam entregar valor e satisfação ao cliente.

No que se refere ao comportamento do consumidor frente às marcas próprias, Harcar, Kara e Kucukemiroglu (2006) afirmam que as marcas próprias desempenham um papel estratégico para os varejistas, e que entender o comportamento do consumidor em relação a estes produtos é uma questão crítica para os profissionais de marketing e pesquisadores do tema.

Fishben e Ajzen (1975) destacam que o foco na atitude, em relação a produtos, lealdade e imagem das marcas, atributos do produto, tem sido o modo de se buscar explicar os vários aspectos da teoria do consumidor. Enquanto o comportamento refere-se, no sentido mais geral, ao movimento ou à reação de qualquer pessoa em relação a seu ambiente ou situação, a atitude refere-se à predisposição a reagir a um estímulo de maneira positiva ou negativa.

Esta definição implica no fato de que as atitudes são aprendidas, ou seja, se formam através da experiência; as atitudes são predisposições que residem na mente do consumidor; as atitudes precedem e produzem o comportamento, pois causam uma resposta consistente, conforme abordado anteriormente (SHETH; MITTAL; NEWMAN, 2001; WELLS; PRENSKY, 1996).

Allport (1935) argumenta que as atitudes determinam para cada indivíduo o que ele fará. Eagly e Chaiken (1993) enfatizam que as atitudes são poderosos indicadores de comportamento, pois a avaliação das atitudes das pessoas se relaciona com o comportamento das mesmas. As pessoas que demonstram atitudes positivas com relação a um objeto, provavelmente se engajam em comportamentos de aproximação, ao contrário das que demonstram atitudes negativas, que adotarão comportamentos de rejeição.

Wells e Prensky (1996) afirmam que os pesquisadores têm utilizado três métodos comuns para medirem as atitudes: observação do comportamento, investigações qualitativas e escala de atitudes. Neste artigo foram adotadas as escalas de atitudes que, de acordo com os autores, são freqüientemente usadas pelos pesquisadores da área.

No que se refere à mensuração da atitude Fishbein e Ajzen (1975) afirmam que a atitude deve ser medida conforme um processo que analisa o sujeito em uma dimensão bipolar afetiva ou avaliativa. Os autores desenvolveram modelos de multriatributos para mensurar a atitude do consumidor. Este trabalho foi inspirado no modelo da Teoria da Ação Racional (TRA) formulado por Fishbein e Ajzen (1975) que mensura as atitudes em relação a comportamentos e determina o papel dessas atitudes na formação dos comportamentos. 
Esta teoria oferece um esquema estruturado para prever e explicar o comportamento humano a partir de um entendimento de suas crenças e atitudes (FISHBEIN; AJZEN, 1975). De acordo com Ajzen e Fishben (1980), a intenção de um indivíduo é definida mediante dois determinantes básicos: a atitude em relação ao comportamento que se refere à avaliação positiva ou negativa que o indivíduo faz a respeito das conseqüências de desencadear o comportamento, e a norma subjetiva que se refere à percepção do indivíduo às pressões sociais postas sobre eles para desenvolver um dado comportamento ou não.

Os autores, para aplicar o modelo, desenvolveram um questionário com escalas quantitativas, sendo a mais comum utilizada para medir atitudes, que consiste em declarações seguidas por grau de concordância (escala de Likert). O consumidor checa a afirmação e indica seu grau de concordância em relação a ela. Assim, são desenvolvidas afirmativas referentes a crenças, que neste trabalho referiam-se aos produtos de marcas próprias, e avaliação das crenças que formavam a atitude, e afirmativas referentes às crenças normativas e a motivação para obedecer que compõem a norma subjetiva para prever a intenção comportamental. Foram levantados na literatura aspectos que poderiam influenciar na atitude do consumidor em relação aos produtos de marcas próprias. Estes aspectos são discutidos a seguir, e posteriormente foi desenvolvido o questionário baseado no modelo da Teoria da Ação Racional.

\subsection{Relacionamento entre atitude e marcas próprias}

A construção de uma marca sólida é um dos objetivos principais das organizações. A compreensão dos fatores que influenciam a atitude do consumidor com a marca tem sido foco de vários estudos na área de marketing, especificamente em relação às marcas próprias.

Dick, Jain e Richardson (1997); Harcar, Kara e Kucukemiroglu (2006) afirmam que os consumidores usam o nome da marca primariamente como uma sugestão para avaliar a qualidade do produto. Dick, Jain e Richardson (1995) ressaltam que os consumidores menos propensos a comprar marcas próprias demonstram menor familiaridade com a marca da loja.

Conforme estudos da Nielsen (COMPRO, 2007 p. 22), no Brasil grandes redes de varejo começam a adotar a estratégia de expor seus produtos de marca própria da mesma forma que expõem produtos de marcas-líderes da indústria, que é uma prática comum nas principais redes de varejo norte-americanas e canadenses.

Dhar e Hoch (1997) afirmam que um suporte promocional para as marcas próprias de um supermercado desenvolve impactos positivos na performance da marca própria. Dick, Jain e Richardson (1995) acreditam que por meio de ações promocionais no ponto-de-venda, pode 
Uma análise dos principais elementos influenciadores da tomada de decisão de compra de produtos de marca própria de supermercados

aumentar a familiaridade com as marcas próprias e, aumentando essa familiaridade, pode-se aliviar a percepção desfavorável ao nível de qualidades desses produtos.

Outro fator de destaque que influencia na atitude do consumidor aos produtos de marca própria é a imagem da loja. Collins-Dodd e Lindley (2003) afirmam que, no contexto de supermercados, se o consumidor tem uma imagem positiva da loja desenvolve uma atitude positiva em torno da marca própria daquele supermercado. Vahie e Paswan (2006) corroboram a afirmação anterior e afirmam que a imagem da atmosfera e a qualidade da loja influenciam na percepção de uma marca própria de qualidade.

Segundo Shannon e Mandachitara (2005), a percepção da marca do varejista tem aumentado a importância quando se refere a marcas próprias de supermercado e possível escolha da loja. Assim, para Vahie e Paswan (2006), a decisão de aplicar ou não a marca da rede nos produtos de marca própria depende da imagem percebida pelos consumidores diante da empresa varejista. Segundo os autores, quando um varejista decide inserir seu nome, nos itens lançados, busca exatamente o benefício de transferência da imagem da rede para seus produtos de marca própria.

Dick, Jain e Richardson (1997) afirmam que os consumidores que acreditam que o nome da marca é um bom indicador do paladar são especialmente menos propensos a comprar marcas próprias. Ressaltam que isto não é surpreendente, uma vez que as marcas próprias são menos conhecidas do que as marcas nacionais, pois falta uma distinta identificação com um determinado fabricante. Porém, Bloemer e Ruyter (1998) afirmam que a imagem da loja pode influenciar a lealdade à loja através da satisfação com a mesma. Pappu e Quester (2006) complementam que a habilidade de lembrar o nome do varejista aumenta com o aumento do nível de satisfação.

Para Hidalgo et al. (2007), os compradores que são leais à loja confiarão em sua loja "eleita" e se familiarizarão com suas marcas próprias, portanto, a lealdade à loja conduz a uma maior probabilidade de êxito das marcas próprias da loja. Huang e Huddleston (2009) complementam que os varejistas que possuem maior grau de participação do cliente, inovação e orientação para marca são mais susceptíveis a obterem maior vantagem com a marca própria, e por sua vez, estão mais propensos a terem mais clientes leais e melhor desempenho financeiro com a marca própria.

Dick, Jain e Richardson (1995) identificaram, que os compradores mais propensos a consumir produtos de marcas próprias "dão mais valor ao dinheiro" do que os não propensos. Ressaltam ainda que isso pode explicar parcialmente por que os não propensos demonstram aversão a comprar produtos de marcas próprias. Burton et al. (1998) afirmam que os 
consumidores que têm uma atitude positiva para os produtos com marca própria são extremamente conscientes dos preços, se vêem como clientes "inteligentes" por procurarem melhores versões de marcas próprias e tendem a se focar quase exclusivamente em pagar preços baixos, minimizando outros fatores na avaliação da marca.

Porém, Souza et al. (2009), cruzando as variáveis preço, qualidade e curiosidade com o perfil do consumidor, constataram que os clientes situados na menor faixa de renda analisada (até R \$1000,00) sofrem mais influência da variável preço, enquanto que os situados nas faixas maiores (acima de $\mathrm{R} \$ 1001,00)$ são mais propensos a comprar marcas próprias por qualidade e curiosidade. A busca de aceitação pelos outros é um aspecto relevante no comportamento de compra dos consumidores de marca própria, de acordo com Machado et al. (2007). Assim, denotar ser um comprador inteligente é importante para esse grupo, o que não diverge do senso comum da busca de uma melhor relação entre custo e benefício. Shannon e Mandachitara (2005) destacam outro aspecto importante sobre o consumidor de marcas próprias, os autores concluíram que a família e ou o grupo de convívio exerce influência na atitude do consumidor frente a estes produtos.

Nota-se que o preço ainda representa um importante papel no que se refere à influência no comportamento do consumidor frente aos produtos de marcas próprias, mas é importante observar o perfil do público-alvo do varejista para definir o posicionamento da marca. Posicionar produtos de marcas próprias apenas por preço pode não proporcionar nenhuma vantagem competitiva entre os varejistas (TOLEDO; GIRALDI; PRADO, 2007).

Lepsch e Silveira (1998) afirmam que os consumidores comparam os produtos com marcas próprias aos produtos mais conhecidos, no momento da decisão de compra. Por esse motivo os preços dos produtos de marca própria sofrem um desconto de $15 \%$ a $20 \%$ que, no Brasil, é elevado devido ao preconceito ainda existente por parte do consumidor em relação às marcas próprias. Carvalho Jr. e Bruni (2007) confirmaram em seu estudo que os produtos de marcas próprias parecem ser comercializados com preço mais baixo em relação às marcas nacionais.

Porém, é comum os consumidores avaliarem a qualidade do produto por meio da percepção de preços. Burton et al. (1998) e Harcar, Kara e Kucukemiroglu (2006) afirmam que o relacionamento da crença entre preço e qualidade das marcas próprias, influencia na atitude do consumidor e essa crença sugere que preços baixos são associados à baixa qualidade. Pereira (2001) justifica essa diferença no preço pelo menor investimento em promoções, menor custo pelo fato da eficiência na distribuição e menor custo de aquisição dos produtos de marcas próprias pelos varejistas. 
Uma análise dos principais elementos influenciadores da tomada de decisão de compra de produtos de marca própria de supermercados

Mieres, Martin e Gutierrez (2006) ressaltam que é essencial que os varejistas retirem a idéia da mente dos consumidores de que as marcas próprias são inferiores em termos de qualidade simplesmente porque seus preços são mais baixos do que as marcas nacionais. Aconselham que os varejistas devam deixar claro que preços mais baixos em suas marcas próprias é conseqüência do resultado de uma grande economia de custos, por exemplo, a forma como é comercializado conforme ressaltado também por Pereira (2001).

Hoch e Banerji (1993) afirmam que as marcas próprias variam muito entre as categorias, tanto no nível de qualidade entre elas quanto na variabilidade desta qualidade dentro da categoria. Segundo o ponto de vista dos autores, entre as categorias de produtos de uma marca própria específica, há categorias em que o varejista desenvolve produtos com maior nível de qualidade, e outras oferecem baixa qualidade. Assim, o varejista não consegue manter o mesmo nível de qualidade dos produtos dentro da categoria criando uma imagem insatisfatória à sua marca própria. Pode-se inferir que a instabilidade no padrão de qualidade e a variabilidade da qualidade dos produtos de marca própria podem deixar os consumidores confusos, fazendo-os optar por produtos de marcas do fabricante.

Neste contexto, Chaniotakis, Lymperopoulos e Soureli (2010) ressaltam que a partir do momento em que a confiança na marca própria é vital na determinação da intenção de compra do consumidor; os gestores de varejo devem tentar desenvolver em seus clientes a confiança em suas marcas, preservando um nível de qualidade para todos os produtos, e enfatizando o processo de seleção e controle de qualidade.

No que se refere à qualidade, este é um fator determinante na escolha entre produtos de marcas próprias e marcas nacionais. De acordo com Richardson, Dick e Jain (1994), a percepção de qualidade nas marcas próprias é um importante elemento para o uso desses produtos e se as marcas de uma categoria são similares em termos de qualidade, há uma tendência no aumento do uso de marcas próprias.

Harcar, Kara e Kucukemiroglu (2006) afirmam que vários estudos concluem que os consumidores mantêm relutância em comprar produtos de marca própria devido à percepção de baixa qualidade em relação a estes produtos. Entretanto, os mesmos afirmam que os estudos atuais estão demonstrando que, devido a uma maior popularidade das marcas próprias, o consumidor tem aumentado a confiança na qualidade desses produtos. Unterleider e Damacena (2006) em sua pesquisa desenvolvida no Brasil, afirmam que a estratégia atual é fornecer produtos de qualidade superior ou igual ao líder, buscando consumidores dispostos a comprar produtos diferenciados e não apenas baratos. Ressaltam que este comportamento tem se tornado um alvo na estratégia dos supermercados. 
O risco percebido é um dos fatores-chaves que levam o consumidor à percepção de inferioridade do produto principalmente quando comparadas com as alternativas de marcas nacionais (DICK; JAIN; RICHARDSON, 1995). Narasimhan e Wilcox (1998) argumentam, ainda, que os consumidores estão menos motivados a comprar marcas próprias em supermercados, se o nível do risco percebido na categoria for alto.

Dick, Jain e Richardson (1995) afirmam que o risco pode se manifestar de diversas maneiras, tais como o medo de um produto não possuir os atributos desejáveis, ou com a incerteza quanto ao desempenho do mesmo ou a sensação de que a compra de determinada marca pode levar a uma reprovação social. Concluem, em seu estudo, que há uma diferença significativa entre os compradores propensos e os não propensos a comprar marcas próprias em relação ao risco percebido. Segundo os autores, os compradores menos propensos são mais temerosos e acreditam que as marcas próprias são inferiores em termos de qualidade, consideram que comprar marcas próprias pode resultar em perdas financeiras, adicionalmente acreditam que pode resultar em uma percepção de que o indivíduo que consome este produto é de uma posição social "inferior".

Mieres, Martín e Gutiérrez (2006) verificaram que quanto maior a igualdade na percepção de qualidade entre marcas próprias e marcas nacionais, maior é a redução do risco percebido entre estas duas marcas. Ainda segundo os autores, a familiaridade com a marca reduz a percepção do risco, ou seja, quanto maior é a familiaridade com a marca própria, menor é a diferença entre essa marca e a marca nacional em termos de risco percebido, independente da categoria de produtos considerada.

Outra implicação na atitude do consumidor com relação aos produtos de marcas próprias refere-se ao programa de comunicação que o varejista utiliza para se comunicar com o consumidor sobre sua marca. Aaker (2001) afirma que uma grande vantagem da marca nacional é o investimento em estratégias que fortalecem a imagem da marca no mercado. Segundo o autor, as marcas nacionais desenvolvem seu prestígio, sua reputação através de grandes campanhas de comunicação. Ressalta que os varejistas têm um orçamento limitado e nem sempre investem na promoção de sua marca, assim provocam uma menor penetração no mercado, e o objetivo de melhorar suas margens e o nível de lealdade do consumidor por meio da marca própria não é alcançado. Souza et al. (2009) complementam que parte dos gerentes de supermercados estão fundamentando suas estratégias de marcas próprias apenas em preço e qualidade, ou seja, não estão fazendo uso das demais estratégias mercadológicas.

A pressão do tempo é um fator ressaltado por alguns autores como influenciadora no comportamento do consumidor durante o processo de compra. Ailawadi, Neslin e Gedenk 
Uma análise dos principais elementos influenciadores da tomada de decisão de compra de produtos de marca própria de supermercados

(2001) afirmam que a pressão do tempo influencia o comportamento do consumidor na escolha entre marcas conhecidas e desconhecidas. Destacam que este fator é enfatizado em locais onde há uma cultura que preza pela minimização do tempo gasto em compras.

Shannon e Mandhachitara (2005) concluíram, em seu estudo, que foram encontradas diferenças culturais relacionadas à orientação do tempo e à como o tempo é avaliado. Segundo os autores, há países mais individualistas e outros mais coletivistas; países em que a ação de comprar é mais demorada e prazerosa e outros em que é mais utilitária e menos prazerosa. Assim, afirmam que a orientação do tempo pode ter várias consequiências. Desta forma, em uma cultura caracterizada por grande pressão do tempo, o prazer de comprar pode ser diminuído e se tornar uma tarefa mais utilitária ou difícil; esta característica é relacionada particularmente para marcas próprias.

Hidalgo et al. (2007) afirmam que os compradores pouco intensivos de marcas próprias se sentem pressionados pelo tempo, o que implica na escassez do tempo para experimentar novas marcas. Assim, os autores sugerem que os varejistas distribuam amostras grátis das marcas próprias com o objetivo de atrair este tipo de consumidor. O Quadro 1 apresenta uma síntese, de acordo com diversos autores sobre os principais fatores que influenciam na atitude do consumidor em relação aos produtos de marca própria:

Quadro 1. Fatores influenciadores na atitude do consumidor em relação a marcas próprias x autores

\begin{tabular}{|l|l|}
\hline \multicolumn{1}{|c|}{ Fatores } & \multicolumn{1}{c|}{ Autores } \\
\hline Preço & $\begin{array}{l}\text { Dick; Jain e Richardson (1995); Lepsch e Silveira (1998); Pereira (2001); Burton et } \\
\text { al. (1998); Harcar; Kara e Kucukemiroglu (2006); Mieres; Martín e Gutiérrez } \\
\text { (2006), Carvalho Jr. e Bruni (2007); Souza et al. (2009) }\end{array}$ \\
\hline Qualidade & $\begin{array}{l}\text { Hoch; Banerj (1993); Richardson; Dick e Jain (1994); Burton et al. (1998); } \\
\text { Shannon e Mandhachitara (2005); Harcar; Kara e Kucukemiroglu (2006); } \\
\text { Unterleider e Damacena (2006); Hidalgo et al. (2007); Machado et al. (2007); } \\
\text { Souza et al. (2009); Chaniotakis, Lymperopoulos e Soureli (2010) }\end{array}$ \\
\hline Risco percebido & $\begin{array}{l}\text { Dick; Jain e Richardson (1995); Narasimhan e Wilcox (1998); Mieres; Martín e } \\
\text { Gutiérrez (2006); Hidalgo et al. (2007). }\end{array}$ \\
\hline Comunicação & $\begin{array}{l}\text { Hoch; Banerj (1993); Richardson; Dick e Jain (1994); Dick; Jain e Richardson } \\
\text { (1995); Dick; Jain e Richardson (1997); Dhar e Hoch (1997); Aaker (2001); } \\
\text { Ailawadi; Neslin e Gendek (2001); Harcar; Kara e Kucukemiroglu (2006); Mieres; } \\
\text { Martín e Gutiérrez (2006); Hidalgo et al. (2007). }\end{array}$ \\
\hline $\begin{array}{l}\text { Imagem da loja e e } \\
\text { lealdade }\end{array}$ & $\begin{array}{l}\text { Dick; Jain e Richardson (1997); Bloemer e Ruyter (1998); Ailawadi; Neslin e } \\
\text { Gendek (2001); Collins-Dodd e Lindley (2003); Shannon e Mandhachitara (2005); } \\
\text { Vahie e Paswan (2006); Pappu e Quester (2006); Hidalgo et al. (2007); Huang e } \\
\text { Huddleston (2009) }\end{array}$ \\
\hline $\begin{array}{l}\text { Pressão do tempo para } \\
\text { comprar }\end{array}$ & $\begin{array}{l}\text { Ailawadi; Neslin e Gendek (2001); Shannon e Mandhachitara (2005); Hidalgo et al. } \\
\text { (2007). }\end{array}$ \\
\hline
\end{tabular}

Fonte: Elaborado pelos autores baseado nos estudos apresentados 


\section{MÉTODO DE PESQUISA}

Como o objetivo principal deste trabalho foi buscar e identificar informações visando a compreensão dos principais elementos influenciadores no comportamento do consumidor frente aos produtos de marcas próprias de supermercado pode-se defini-lo como exploratório (MALHOTRA, 2006). Adicionalmente, buscou proporcionar conhecimento das variáveis que podem estar relacionadas ao tema e maior familiaridade com o problema de pesquisa. Desta forma, o tipo de pesquisa adotado para o alcance do objetivo deste estudo foi predominantemente exploratório com aspectos descritivos.

A pesquisa de campo, com abordagem quantitativa, foi desenvolvida por meio de medidas de opinião que objetivaram avaliar os elementos influenciadores no comportamento do consumidor frente aos produtos de marca própria. Foram utilizados formulários estruturados com perguntas utilizando uma escala de Likert, enviados por correio eletrônico para um banco de e-mails selecionado. Para o aumento do índice de respostas, foi feita uma doação, para cada questionário preenchido, para o Grupo de Apoio à Criança com Câncer de Ribeirão Preto (GACC), conforme destacado no convite da pesquisa.

$\mathrm{O}$ questionário adotado foi dividido em sete partes. $\mathrm{Na}$ primeira parte objetivou caracterizar o entrevistado, ou seja, conhecer o seu perfil social por meio de questões com uma única alternativa de resposta. Já na segunda parte, o objetivo foi conhecer as crenças dos consumidores em relação aos produtos de marcas próprias. Foram desenvolvidas 15 crenças e cada uma foi mensurada em uma escala de cinco pontos de Likert. Na terceira parte, 15 afirmações mediaram a avaliação das crenças; manteve-se a mesma escala. Os aspectos, presentes nas crenças e nas avaliações das crenças foram baseados em estudos realizados sobre comportamento do consumidor em relação às marcas próprias, apresentados no tópico anterior deste artigo. A quarta e quinta partes do questionário abrangiam afirmações sobre crenças normativas e motivações para obedecer que incluíam algumas pessoas do grupo de referência que poderiam ser importantes e influenciar no comportamento de compra dos consumidores. Já na sexta parte foi mensurada a intenção de compra de marcas próprias e na sétima avaliou-se o grau de satisfação com estes produtos, mantendo-se a escala de cinco pontos.

A fase de pré-teste para avaliar o nível de eficiência do formulário foi desenvolvida com 96 consumidores dos produtos de marcas próprias, cujas sugestões foram incorporadas no questionário da pesquisa. Dado que não foram encontrados problemas significativos de interpretação e sugestões de novas variáveis, optou-se pela implantação direta do questionário quantitativo, realizados os ajustes. O modelo de questionário adotado, conforme ressaltado 
Uma análise dos principais elementos influenciadores da tomada de decisão de compra de produtos de marca própria de supermercados

anteriormente, foi inspirado na teoria da ação racional formulada por Fishbein e Ajzen (1975) e desta forma foram construídas assertivas sobre as crenças dos consumidores em relação às marcas próprias, avaliações destas crenças, normas subjetivas e motivações para obedecer para inferir sobre os principais fatores que influenciam na intenção comportamental.

A técnica amostral adotada foi a não probabilística por conveniência, utilizando questionário auto-administrado via internet. Foi desenvolvido e enviado pela internet o convite para preenchimento da pesquisa para cerca de 9.000 e-mails em todo o Brasil, base de dados referentes a alunos relacionados às Instituições de Ensino Superior. Foram obtidos 1072 questionários respondidos, sendo que 89 foram descartados por falhas no preenchimento e 983 foram validados, ou seja, $11 \%$ do total de e-mails enviados retornaram preenchidos corretamente. A amostra foi obtida durante o período de dois meses do ano de 2009.

\section{ANÁLISE E DISCUSSÃO DOS RESULTADOS}

Para análise dos dados, inicialmente realizou-se a análise descritiva da amostra, obtendo-se seu perfil. A seguir utilizando-se o pacote estatístico SPSS (statistical package for social sciences) foi realizada a análise fatorial para definir um conjunto de fatores e por fim, aplicou-se testes de média para verificar a ocorrência de diferença significativa entre os fatores para o sexo, escolaridade e faixa etária dos respondentes. A tabela 1 apresenta as frequiências de casos por sexo, faixa etária, escolaridade e Estado de origem. 
Lúcia Aparecida da Silva, Edgard Monforte Merlo \& Marcelo Seido Nagano

Tabela 1 - Dados demográficos da amostra

\begin{tabular}{|c|c|}
\hline Características demográficas & Porcentagem da amostra \\
\hline \multicolumn{2}{|l|}{ r } \\
\hline Feminino & 49,8 \\
\hline Masculino & 50,2 \\
\hline \multicolumn{2}{|c|}{ Faixa etária } \\
\hline Entre 18 e 26 anos & 37,8 \\
\hline 27 a 35 anos & 33,8 \\
\hline 36 a 44 anos & 13,9 \\
\hline 45 a 53 anos & 10,2 \\
\hline$>$ que 53 anos & 4,3 \\
\hline \multicolumn{2}{|c|}{ Escolaridade } \\
\hline Primário completo/Ginasial incompleto & 0,5 \\
\hline Ginasial completo/Colegial incompleto & 4,9 \\
\hline Colegial completo/Superior incompleto & 27,8 \\
\hline Superior completo & 22,0 \\
\hline Pós-graduado/Especialização & 20,9 \\
\hline Mestrado/Doutorado & 24,0 \\
\hline \multicolumn{2}{|c|}{ Estado Civil } \\
\hline Casado & 32,3 \\
\hline Solteiro & 57,5 \\
\hline Separado & 5,4 \\
\hline Outros & 4,8 \\
\hline \multicolumn{2}{|c|}{ Estado de origem } \\
\hline São Paulo & 42,4 \\
\hline Minas Gerais & 16,1 \\
\hline Paraná & 5,4 \\
\hline Rio Grande do Sul & 5,4 \\
\hline Rio de Janeiro & 5,3 \\
\hline Outros & 25,4 \\
\hline
\end{tabular}

Fonte: dados da pesquisa

Em relação ao estado civil, a maior parte da amostra é solteira (58\%), seguida de $32 \%$ que são casados, separados (5\%) e outros (5\%). O grande número de pessoas solteiras pode-se relacionar à faixa etária, conforme abordada anteriormente que é composta em sua maioria por pessoas com até 35 anos. Analisando-se a totalidade das respostas recebidas (983), grande parte originou-se do Estado de São Paulo (42\%), seguido de Minas Gerais (16\%), Paraná e Rio Grande do Sul (5\%), Rio de Janeiro (5\%) e dos demais Estados (25\%) da amostra. Ressalta-se que a amostra teve origem de 26 Estados do Brasil.

Aplicou-se a análise de componentes principais com método de rotação ortogonal Varimax, para verificação de existência de dimensões latentes nos dados. Obtiveram-se 10 fatores com autovalor maior que um, que explicam $61 \%$ da variância dos dados. A medida de adequacidade da amostra $\mathrm{KMO}=0,876$ foi considerada adequada, e o teste de Bartlett rejeitou a hipótese nula, ou seja, a matriz de correlação não pode ser considerada uma matriz identidade, assim a ferramenta análise fatorial pode ser aplicada aos dados. As medidas individuais de adequacidade das variáveis foram acima de 0,5, o que pode ser considerado adequado. Os fatores obtidos são apresentados na Tabela 2. 
Uma análise dos principais elementos influenciadores da tomada de decisão de compra de produtos de marca própria de supermercados

Tabela 2 - Representação dos fatores obtidos

\begin{tabular}{|c|c|c|c|}
\hline Fator & $\begin{array}{l}\text { Coeficiente } \\
\text { alfa de } \\
\text { Cronbach }\end{array}$ & Variáveis & $\begin{array}{l}\text { Carga } \\
\text { fatorial }\end{array}$ \\
\hline \multirow[t]{4}{*}{$\begin{array}{l}\text { Risco percebido e } \\
\text { qualidade }\end{array}$} & \multirow[t]{5}{*}{0,433} & $\begin{array}{l}\text { Fico inseguro(a) quando compro produtos de marca } \\
\text { própria porque acho que o risco é maior. }\end{array}$ & 0,733 \\
\hline & & $\begin{array}{l}\text { Fico inseguro(a) para comprar produtos alimentícios } \\
\text { de marca própria. }\end{array}$ & 0,699 \\
\hline & & $\begin{array}{l}\text { Comprar produtos de marca própria é muito bom } \\
\text { porque a qualidade é tão boa quanto as marcas } \\
\text { nacionais. }\end{array}$ & $-0,667$ \\
\hline & & $\begin{array}{l}\text { Quando vejo um produto de marca própria com preço } \\
\text { baixo, tenho a sensação de que a qualidade daquele } \\
\text { produto é ruim. }\end{array}$ & 0,654 \\
\hline \multirow{10}{*}{$\begin{array}{l}\text { Tabela } 2 \text { - Represe } \\
\text { Continuação }\end{array}$} & & $\begin{array}{l}\text { Considero mais arriscado comprar produtos } \\
\text { oblidos } \\
\text { alimentícios de marca própria. }\end{array}$ & 0,639 \\
\hline & \multirow{9}{*}{ tação dos fatores } & $\begin{array}{l}\text { As marcas próprias são similares em termos de } \\
\text { qualidade às marcas nacionais. }\end{array}$ & $-0,633$ \\
\hline & & $\begin{array}{l}\text { Para mim os produtos de marca própria representam } \\
\text { um maior risco no momento da compra. }\end{array}$ & 0,627 \\
\hline & & $\begin{array}{l}\text { Quando compro produtos de marca própria, tenho a } \\
\text { sensação de ter feito um bom negócio porque os } \\
\text { produtos têm alta qualidade. }\end{array}$ & $-0,626$ \\
\hline & & $\begin{array}{l}\text { Os produtos de marca própria de supermercado por } \\
\text { terem preço mais baixo, têm baixa qualidade. }\end{array}$ & 0,596 \\
\hline & & $\begin{array}{l}\text { Minha família acha que comprar produtos de marca } \\
\text { própria é muito arriscado. }\end{array}$ & 0,534 \\
\hline & & As marcas próprias são sinônimas de qualidade. & $-0,511$ \\
\hline & & $\begin{array}{l}\text { Os produtos de marca própria variam muito em termos } \\
\text { de qualidade. }\end{array}$ & 0,441 \\
\hline & & $\begin{array}{l}\text { Por existir grande variação na qualidade dos produtos } \\
\text { de marca própria, a imagem da marca é prejudicada. }\end{array}$ & 0,429 \\
\hline & & $\begin{array}{l}\text { Comprar produtos de marca própria com preço baixo é } \\
\text { muito bom. }\end{array}$ & $-0,422$ \\
\hline \multirow[t]{6}{*}{ Imagem da loja } & \multirow[t]{6}{*}{0,863} & $\begin{array}{l}\text { Quando a loja é limpa, bem organizada atribuo maior } \\
\text { qualidade aos produtos com sua marca própria. }\end{array}$ & 0,788 \\
\hline & & $\begin{array}{l}\text { Quando a loja tem uma boa imagem no mercado, } \\
\text { atribuo maior confiança aos produtos com sua marca } \\
\text { própria. }\end{array}$ & 0,764 \\
\hline & & $\begin{array}{l}\text { Comprar produtos de marca própria é melhor quando } \\
\text { já conhecemos bem o supermercado que está } \\
\text { vendendo estes produtos. }\end{array}$ & 0,746 \\
\hline & & $\begin{array}{l}\text { Uma loja que tem uma boa imagem junto à } \\
\text { comunidade transmite maior confiança aos produtos } \\
\text { de sua marca própria. }\end{array}$ & 0,732 \\
\hline & & $\begin{array}{l}\text { Uma loja limpa e organizada transmite maior } \\
\text { confiança aos produtos de marca própria vendidos. }\end{array}$ & 0,707 \\
\hline & & $\begin{array}{l}\text { Se eu tenho bom conhecimento do supermercado, } \\
\text { tenho mais disposição para comprar os seus produtos } \\
\text { de marca própria. }\end{array}$ & 0,664 \\
\hline \multirow[t]{3}{*}{$\begin{array}{l}\text { Influências de } \\
\text { pessoas próximas }\end{array}$} & \multirow[t]{3}{*}{0,769} & $\begin{array}{l}\text { As pessoas que moram em minha casa acham que } \\
\text { comprar produtos de marcas próprias vale a pena. }\end{array}$ & 0,767 \\
\hline & & $\begin{array}{l}\text { As pessoas que moram em minha casa acham que, se } \\
\text { eu usar produtos de marca própria, serei mais } \\
\text { econômico(a). }\end{array}$ & 0,738 \\
\hline & & $\begin{array}{l}\text { Minha família acha que usar produtos de marca } \\
\text { própria é muito bom. }\end{array}$ & 0,717 \\
\hline
\end{tabular}


Lúcia Aparecida da Silva, Edgard Monforte Merlo \& Marcelo Seido Nagano

\begin{tabular}{|c|c|c|c|}
\hline Fator & $\begin{array}{l}\text { Coeficiente } \\
\text { alfa de } \\
\text { Cronbach }\end{array}$ & Variáveis & $\begin{array}{l}\text { Carga } \\
\text { fatorial }\end{array}$ \\
\hline & & $\begin{array}{l}\text { Meus vizinhos acham que produtos de marcas } \\
\text { próprias são de boa qualidade. }\end{array}$ & 0,503 \\
\hline \multirow{3}{*}{$\begin{array}{l}\text { Opinião de } \\
\text { pessoas próximas } \\
\text { (Motivação para } \\
\text { obedecer) }\end{array}$} & \multirow[t]{3}{*}{0,7} & $\begin{array}{l}\text { É importante para mim o que as pessoas que moram } \\
\text { em minha casa acham de mim. }\end{array}$ & 0,903 \\
\hline & & $\begin{array}{l}\text { É importante para mim o que a minha família acha de } \\
\text { mim. }\end{array}$ & 0,882 \\
\hline & & $\begin{array}{l}\text { É importante para mim o que os meus vizinhos acham } \\
\text { de mim. }\end{array}$ & 0,485 \\
\hline \multirow[t]{2}{*}{ Pressão do tempo } & \multirow[t]{2}{*}{0,809} & $\begin{array}{l}\text { O tempo que tenho para comprar influencia na escolha } \\
\text { da marca. Se tenho pouco tempo, prefiro escolher uma } \\
\text { marca nacional conhecida a uma marca própria. }\end{array}$ & 0,884 \\
\hline & & $\begin{array}{l}\text { Quando tenho pouco tempo para fazer compras, } \\
\text { compro marcas conhecidas ao invés de marcas } \\
\text { próprias. }\end{array}$ & 0,844 \\
\hline \multirow[t]{2}{*}{$\begin{array}{l}\text { Categorias de } \\
\text { produto }\end{array}$} & \multirow[t]{2}{*}{0,689} & $\begin{array}{l}\text { Considero menos arriscado comprar produtos de } \\
\text { limpeza de marca própria. }\end{array}$ & 0,842 \\
\hline & & $\begin{array}{l}\text { Comprar produtos de limpeza de marcas própria é } \\
\text { menos arriscado. }\end{array}$ & 0,827 \\
\hline \multirow[t]{3}{*}{ Qualidade e preço } & \multirow[t]{3}{*}{0,668} & $\begin{array}{l}\text { A qualidade dos produtos de marca própria é mais } \\
\text { importante do que o preço atribuído a eles. }\end{array}$ & 0,845 \\
\hline & & Quando compro um produto de marca própria, & 0,826 \\
\hline & & $\begin{array}{l}\text { considero a qualidade mais importante do que o preço } \\
\text { do produto. }\end{array}$ & Continua \\
\hline \multirow[t]{2}{*}{ Lealdade à loja } & \multirow[t]{2}{*}{0,76} & $\begin{array}{l}\text { Se sou leal ao supermercado, compro produtos de sua } \\
\text { marca própria. }\end{array}$ & 0,784 \\
\hline & & $\begin{array}{l}\text { Quando sou leal a um supermercado, tenho maior } \\
\text { disposição para comprar produtos de sua marca } \\
\text { própria. }\end{array}$ & 0,698 \\
\hline \multirow[t]{3}{*}{$\begin{array}{l}\text { Comunicação e } \\
\text { preço }\end{array}$} & \multirow[t]{3}{*}{0,45} & $\begin{array}{l}\text { Produtos de marca própria do supermercado têm preço } \\
\text { baixo. }\end{array}$ & 0,594 \\
\hline & & $\begin{array}{l}\text { As marcas próprias de supermercado que são mais } \\
\text { divulgadas junto ao consumidor transmitem maior } \\
\text { confiança. }\end{array}$ & 0,504 \\
\hline & & $\begin{array}{l}\text { Quando as marcas fazem muitas propagandas, } \\
\text { promoções e estão sempre comunicando comigo, } \\
\text { desenvolvo maior confiança nesta marca própria. }\end{array}$ & 0,481 \\
\hline $\begin{array}{l}\text { Opinião negativa } \\
\text { de vizinhos }\end{array}$ & $\begin{array}{l}\text { * não é } \\
\text { possível obter } \\
\text { o coeficiente } \\
\text { alfa para } \\
\text { fatores com } \\
\text { apenas uma } \\
\text { variável }\end{array}$ & $\begin{array}{l}\text { Meus vizinhos acham que, se eu comprar produtos de } \\
\text { marcas próprias, estarei perdendo dinheiro. }\end{array}$ & 0,638 \\
\hline
\end{tabular}

Fonte: dados da pesquisa

O fator um risco percebido e qualidade foi composto de variáveis referentes ao risco de se consumirem marcas próprias, à qualidade dos produtos, à variabilidade desses produtos e à imagem de preço baixo em relação à qualidade dos produtos de marcas próprias. De acordo com Dick, Jain e Richardson (1995) o risco percebido exerce influência no comportamento de compra do consumidor e este risco pode-se manifestar de várias maneiras, uma delas é pelo medo de o produto não possuir atributos desejados. Assim, quando o 
Uma análise dos principais elementos influenciadores da tomada de decisão de compra de produtos de marca própria de supermercados

consumidor se depara com produtos de marcas próprias com preços mais baixos relaciona este fator à baixa qualidade, considerando arriscado comprar o produto por medo do nível da qualidade do mesmo, conforme abordado por Burton et al. (1998) e Harcar, Kara e Kucukemiroglu (2006). Outro aspecto relacionado ao risco é a variação na qualidade dos produtos de marcas próprias, tanto dentro da categoria quanto entre categorias diferentes como alimentos e limpeza, que de acordo com Hoch e Banerji (1993), nas categorias que apresentam grande diferença na qualidade entre marcas próprias e marcas nacionais o market share das marcas próprias é menor em comparação com aquelas categorias em que as marcas próprias aproximam-se em termos de qualidade das marcas nacionais. Quando a conseqüência em consumir um produto é mais grave, o consumidor tende a consumir marcas tradicionais pelo medo de arriscar.

O fator dois denominado de imagem da loja se refere aos atributos da loja como a organização, a limpeza, a lealdade à loja e o conhecimento da loja. O consumidor tende a transferir a imagem da loja para os seus produtos de marca própria conforme abordado nos estudos de Dick, Jain e Richardson (1997); Bloemer e Ruyter (1998); Collins-Dodd e Lindley (2003); Shannon e Mandachitara (2005) e Pappu e Quester (2006). Assim, se a loja desenvolve ações que proporcionem imagem agradável aos consumidores, estes desenvolverão atitude mais positiva à loja e consequentemente aos seus produtos de marcas próprias, conforme destacado por Dick, Jain e Richardson (1995); Vahie e Paswan (2006) e Huang e Huddleston (2009).

$\mathrm{O}$ fator três chamado de influência de pessoas próximas, se refere à influência positiva de pessoas da família, co-habitantes e vizinhança em relação a produtos de marca própria. No grupo de referência, principalmente as pessoas mais próximas influenciam o comportamento de compra, de forma positiva conforme abordado por Shannon e Mandachitara (2005).

O fator quatro denominado de opinião de pessoas próximas refere-se ao grau de importância da opinião das pessoas próximas no comportamento de compra de produtos de marcas próprias, ou seja, o grau de disposição em aceitar a opinião dessas pessoas.

O fator cinco chamado de pressão do tempo, trata de variáveis relativas ao tempo disponível do cliente para realizar suas compras e escolher entre marcas conhecidas e desconhecidas conforme abordado por Ailawadi, Neslin e Gedenk (2001). Em países com uma cultura caracterizada por grande pressão do tempo, o prazer de comprar tende a ser diminuído, tornando a tarefa mais utilitária. Assim, quanto menor o tempo disponível, menor a disposição do cliente em comprar marcas próprias. Quando as pessoas passam mais tempo 
comprando, tendem a experimentar novas marcas e a compará-las, conforme abordado nos estudos de Shannon e Mandhachitara (2005) e Hidalgo et al. (2007).

O fator seis denominado de categorias de produtos possui variáveis relativas ao risco de comprar produtos da categoria de limpeza. Algumas categorias de produto possuem menor risco percebido, tal como produtos de limpeza. Porém, quando se trata de produtos de categorias como a alimentícia, principalmente perecíveis, a percepção de risco é maior, que de acordo com Narasimhan e Wilcox (1998) os consumidores estarão menos dispostos a comprar se o risco percebido na categoria for alto.

$\mathrm{O}$ fator sete chamado de qualidade e preço, apresenta variáveis que comparam preço e qualidade dos produtos de marca própria, sendo que a qualidade é considerada mais importante do que o preço do produto. Conforme Burton et al. (1998) e Harcar, Kara e Kucukemiroglu (2006), o consumidor, ao comprar produtos de marcas próprias, compara preço e qualidade. Porém, prefere comprar produtos de marcas próprias de qualidade a adquirir produtos de baixo preço que não o deixarão satisfeito em relação a este atributo.

$\mathrm{O}$ fator oito denominado de lealdade à loja refere-se às variáveis que relacionam a lealdade e a disposição de compra naquela loja. De acordo com Hidalgo et al. (2007), quanto maior o grau de lealdade à loja, maior a disposição em comprar produtos de marca própria daquela loja. Assim, mesmo que o consumidor não conheça os produtos de marcas próprias da loja, tende a transferir a lealdade da loja para as marcas próprias.

O fator nove chamado de comunicação e preço, trata do nível de comunicação de produtos de marca própria, quanto maior a comunicação, maior a confiança, conforme destacado por Dhar e Hoch (1997). Apresenta também uma variável que trata da percepção de preço baixo dos produtos de marca própria. $\mathrm{O}$ alto nível de comunicação pode aumentar o custo do produto, o que se reflete no preço de venda, Pereira (2001) ressalta que um dos motivos da prática de preço baixo em marcas próprias é o baixo investimento em promoções. Se houver uma aproximação entre os preços de produtos de marcas próprias e as nacionais, o consumidor tende a preferir os produtos de marcas nacionais.

Finalizando, o fator 10 foi composto de apenas uma variável que trata da opinião negativa de vizinhos em relação aos produtos de marcas próprias. Denota que a opinião negativa de vizinhos não influencia no comportamento do consumidor em relação às marcas próprias, ao contrário das opiniões positivas. A seguir é apresentado quadro com uma breve descrição dos dados coletados. 
Uma análise dos principais elementos influenciadores da tomada de decisão de compra de produtos de marca própria de supermercados

Quadro 4. Estatísticas descritivas dos fatores

\begin{tabular}{|c|c|c|c|c|c|}
\hline & Mínimo & Máximo & Média & $\begin{array}{c}\text { Desvio- } \\
\text { padrão }\end{array}$ & $\begin{array}{c}\text { Coeficiente de } \\
\text { variação }\end{array}$ \\
\hline Fator 1 & 1,79 & 5,00 & 2,9044 &, 37819 & $13 \%$ \\
Fator 2 & 1,00 & 5,00 & 3,9541 &, 75558 & $19,1 \%$ \\
Fator 3 & 1,00 & 5,00 & 3,1615 &, 74381 & $23,5 \%$ \\
Fator 4 & 1,00 & 5,00 & 2,8149 &, 98889 & $35,1 \%$ \\
Fator 5 & 1,00 & 5,00 & 3,2681 & 1,19917 & $36,7 \%$ \\
Fator 6 & 1,00 & 5,00 & 2,6801 &, 97532 & $36,4 \%$ \\
Fator 7 & 1,00 & 5,00 & 3,3535 & 1,03227 & $30,8 \%$ \\
Fator 8 & 1,00 & 5,00 & 2,8713 & 1,11460 & $38,8 \%$ \\
Fator 9 & 1,00 & 5,00 & 3,3978 &, 72872 & $21,4 \%$ \\
Fator 10 & 1,00 & 5,00 & 2,5890 &, 80853 & $31,2 \%$ \\
\hline
\end{tabular}

Fonte: dados da pesquisa

Em geral os fatores apresentam médias relativamente baixas, variando entre 2, 5 e 4,0. O fator dois, imagem da loja, possui a maior média, ou seja, há maior concordância de que os atributos relacionados à loja exercem maior influência sobre a confiança e disposição em comprar produtos de marca própria da loja. O fator nove, comunicação e preço, possui a segunda maior média, assim a comunicação poder ser considerada um atributo importante para atribuição de confiança na marca. $\mathrm{O}$ fator sete, qualidade e preço, possui a terceira maior média, o que indica que o consumidor atribui maior importância ao atributo qualidade ao preço. A Figura 2 apresenta a distribuição das notas em cada um dos fatores.

Figura 2. Distribuição das notas por fator

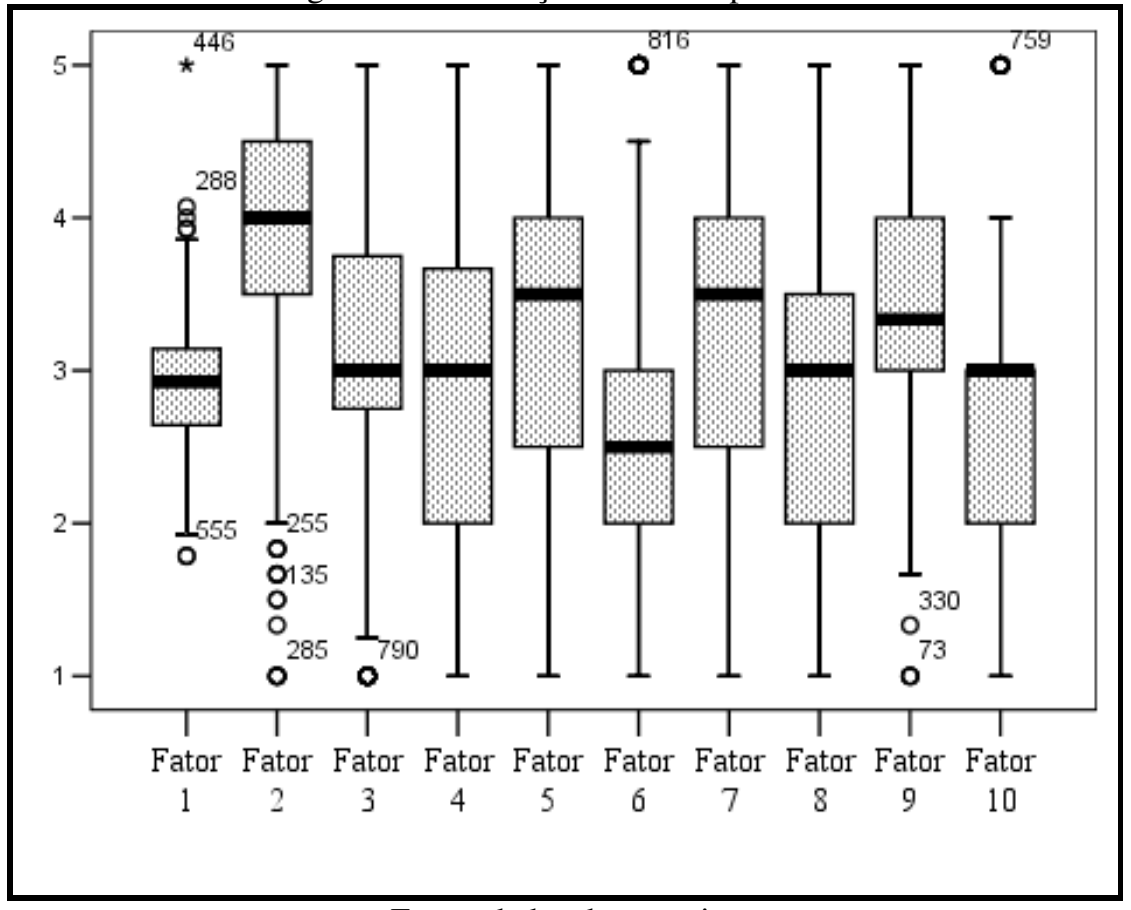

Fonte: dados da pesquisa 
Lúcia Aparecida da Silva, Edgard Monforte Merlo \& Marcelo Seido Nagano

Aplicou-se um teste de significância para duas amostras independentes para verificar se existe diferença significativa de comportamento entre homens e mulheres, em relação aos produtos de marcas próprias em cada fator obtido na análise fatorial. Utilizou-se o teste tstudent e verificou-se pelo teste de Levene, com nível de significância de $1 \%$, que as variâncias podem ser consideradas iguais, o que permite a utilização do teste. Os resultados obtidos são apresentados no Quadro 5, ao nível de significância de 5\%.

As hipóteses do teste são:

$\mathrm{H}_{0}$ : não existe diferença de média entre homens e mulheres nos fatores

$\mathrm{H}_{1}$ : existe diferença significativa de média entre homens e mulheres em cada fator

Quadro 5. Teste t-student para variável sexo

\begin{tabular}{|l|c|c|c|}
\hline \multicolumn{1}{|c|}{ Fator } & Estatística t-student & p-valor & Decisão \\
\hline $\begin{array}{l}\text { 1- risco percebido e } \\
\text { qualidade }\end{array}$ & 1,25 & 0,21 & Não se rejeita $\mathrm{H}_{0}$ \\
\hline 2 - imagem da loja & 3,31 & 0,001 & Rejeita-se $\mathrm{H}_{0}$ \\
\hline $\begin{array}{l}3 \text { - influência de pessoas } \\
\text { próximas }\end{array}$ & 2,43 & 0,015 & Rejeita-se $\mathrm{H}_{0}$ \\
\hline $\begin{array}{l}4 \text { - opinião de pessoas } \\
\text { próximas }\end{array}$ & $-1,67$ & 0,094 & Não se rejeita $\mathrm{H}_{0}$ \\
\hline 5 - pressão do tempo & 0,77 & 0,436 & Não se rejeita $\mathrm{H}_{0}$ \\
\hline $\begin{array}{l}6 \text { - categoria de } \\
\text { produtos }\end{array}$ & 0,704 & 0,481 & Não se rejeita $\mathrm{H}_{0}$ \\
\hline 7 - qualidade e preço & 2,37 & 0,018 & Rejeita-se $\mathrm{H}_{0}$ \\
\hline 8 - lealdade à loja & 2,15 & 0,032 & Rejeita-se $\mathrm{H}_{0}$ \\
\hline 9 - comunicação e preço & 2,82 & 0,005 & Rejeita-se $\mathrm{H}_{0}$ \\
\hline $\begin{array}{l}10 \text { - opinião negativa de } \\
\text { vizinhos }\end{array}$ & $-0,44$ & 0,658 & Não se rejeita $\mathrm{H}_{0}$ \\
\hline
\end{tabular}

Fonte: dados da pesquisa

Observou-se a existência de diferença significativa entre homens e mulheres apenas nos fatores 2, 3, 7, 8 e 9. As estatísticas descritivas, apresentadas no Quadro 6, mostram que, nestes fatores, a média das mulheres é maior que a dos homens, ou seja, elas possuem opinião mais positiva que os homens em relação à imagem da loja, influência de pessoas próximas, importância da qualidade em relação ao preço, lealdade à loja e ao nível de comunicação na predisposição de comprar produtos de marcas próprias. 
Uma análise dos principais elementos influenciadores da tomada de decisão de compra de produtos de marca própria de supermercados

Quadro 6. Estatística descritiva dos fatores por sexo

\begin{tabular}{|l|c|c|c|c|}
\hline Fator & Sexo & Média & $\begin{array}{c}\text { Desvio- } \\
\text { padrão }\end{array}$ & $\begin{array}{c}\text { Coeficiente de } \\
\text { variação }\end{array}$ \\
\hline \multirow{2}{*}{ 2 - Imagem da loja } & Feminino & 4,03 & 0,75 & $18,6 \%$ \\
\cline { 2 - 5 } & Masculino & 3,87 & 0,75 & $19,4 \%$ \\
\hline \multirow{2}{*}{ 3 - Influência de pessoas próximas } & Feminino & 3,21 & 0,74 & $23,1 \%$ \\
\cline { 2 - 5 } & Masculino & 3,10 & 0,73 & $23,5 \%$ \\
\hline \multirow{2}{*}{ 7 - Qualidade e preço } & Feminino & 3,43 & 1,04 & $30,3 \%$ \\
\cline { 2 - 5 } & Masculino & 3,27 & 1,01 & $30,9 \%$ \\
\hline \multirow{2}{*}{ 8 - Lealdade à loja } & Feminino & 2,94 & 1,13 & $38,4 \%$ \\
\cline { 2 - 5 } & Masculino & 2,79 & 1,09 & $39,1 \%$ \\
\hline \multirow{2}{*}{ 9 - Comunicação e preço } & Feminino & 3,46 & 0,71 & $20,5 \%$ \\
\cline { 2 - 5 } & Masculino & 3,33 & 0,73 & $21,9 \%$ \\
\hline
\end{tabular}

Fonte: dados da pesquisa

A Erro! Fonte de referência não encontrada., por meio do gráfico box plot apresenta a distribuição das notas em cada fator para os sexos masculino e feminino.

Figura 4. Distribuição dos fatores por sexo

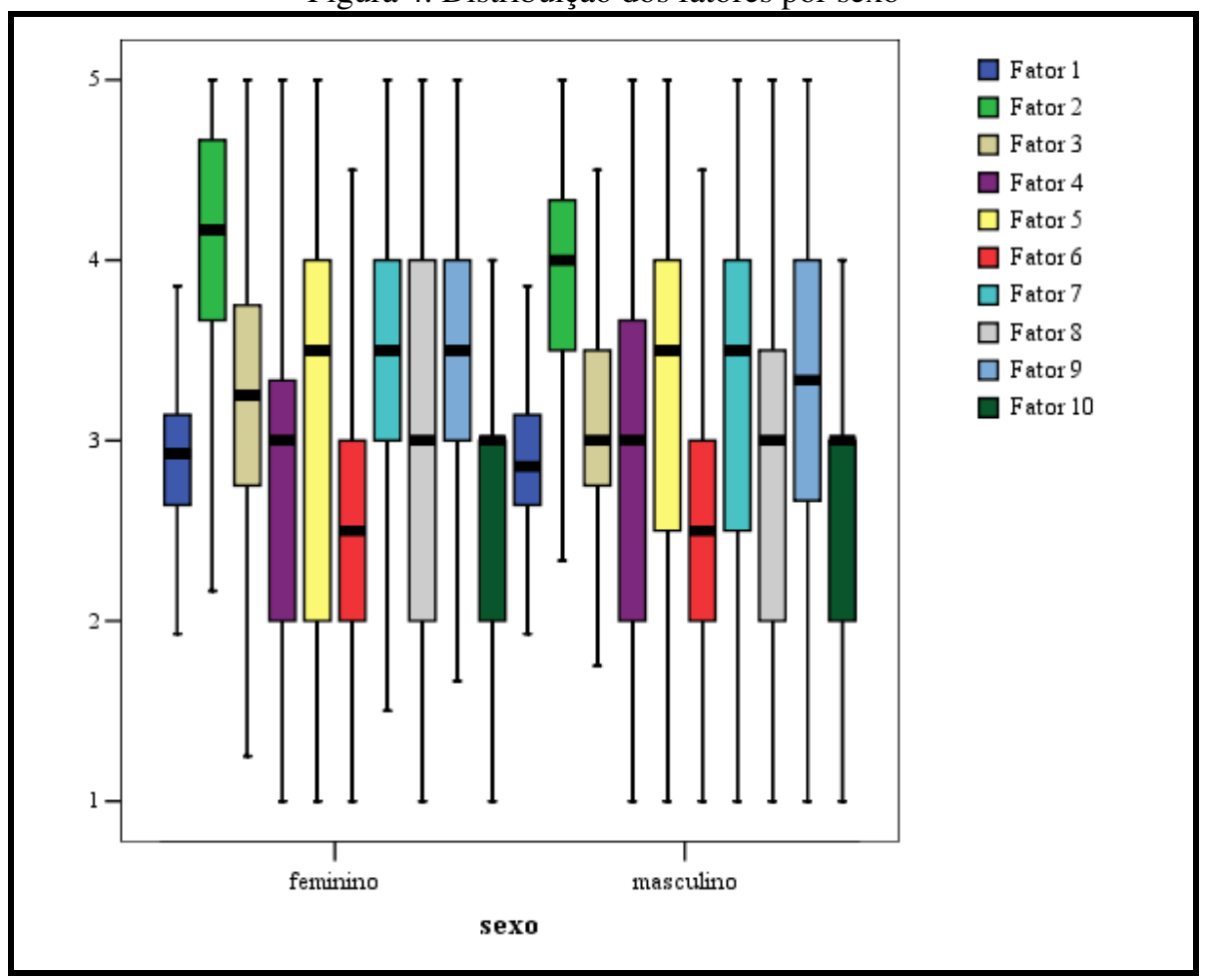

Fonte: dados da pesquisa

Realizaram-se testes de média para as variáveis faixas etárias e níveis de escolaridade, porém não foram observadas diferenças significativas entre as categorias das variáveis em cada fator. 
Lúcia Aparecida da Silva, Edgard Monforte Merlo \& Marcelo Seido Nagano

\section{CONSIDERAÇÕES FINAIS}

No tocante à atitude frente às marcas próprias, infere-se que vários fatores influenciam na formação da atitude do consumidor em relação aos produtos de marcas próprias. Desta forma, os elementos que influenciam na atitude do consumidor abordados nas literaturas são: embalagem, preço e qualidade, familiaridade dos usuários com a marca, recomendação do grupo de convívio, comunicação da marca, aceitação social, risco percebido, variação na qualidade, pressão do tempo para comprar, imagem da loja e lealdade.

Os dez fatores obtidos com a aplicação da análise fatorial foram: risco percebido e qualidade, imagem da loja, influências de pessoas próximas, opinião de pessoas próximas (motivação para obedecer), pressão do tempo, categorias de produtos, qualidade e preço, lealdade à loja, comunicação e preço e opinião negativa de vizinhos.

As medidas dos fatores foram baixas, porém o fator referente à imagem da loja, comunicação e preço, qualidade e preço são os que apresentaram maiores médias respectivamente. Isto significa que os respondentes concordam que estes fatores são importantes e exercem maior influência em seu comportamento. Conclui-se, então, que a imagem da loja, sua limpeza e organização, bem como o maior conhecimento e a familiaridade com a loja proporcionados por meio da utilização de ferramentas de comunicação e o nível de qualidade dos produtos são os fatores que mais influenciam na disposição dos consumidores para comprar e confiar na marca própria da loja.

Com relação às variáveis, sexo, faixa etária e escolaridade, não se observaram diferenças significativas nas opiniões dos respondentes por faixa etária e escolaridade. Constatou-se que há diferenças significativas apenas na variável sexo, nos fatores imagem da loja, influência de pessoas próximas, maior importância da qualidade em relação ao preço, lealdade à loja e nível de comunicação. O que torna possível concluir que, com respeito a esses fatores, a média das mulheres é maior do que a dos homens. Assim elas possuem uma opinião mais positiva de que estes fatores exercem maior influência na sua intenção comportamental do que os homens.

Dessa forma, pode-se inferir que os varejistas devem investir nos fatores que influenciam na imagem da loja, como a atmosfera da loja, serviços ao consumidor, reputação, merchandising e outros. Porém, é importante lembrar-se de que estes fatores contribuem para a construção de melhor imagem da marca própria e invocam o consumidor para experimentar estes produtos, mas, caso eles encontrem produtos de qualidade ruim que não estejam de acordo com a imagem transmitida pela loja, não continuarão adquirindo o produto simplesmente pelo fato de a atmosfera da loja ser agradável. 
Uma análise dos principais elementos influenciadores da tomada de decisão de compra de produtos de marca própria de supermercados

Os varejistas devem, também, desenvolver ações de comunicação que contemplem propagandas, merchandising, testes de sabor, publicidade, promoções de vendas por meio de amostras grátis e degustações, para que gerem maior experimentação e conhecimento da marca, pois, campanhas promocionais familiarizam o consumidor com as marcas e encorajam as compras-testes, estimulando uma experiência inicial com o produto. Conclui-se que estas ações podem influenciar positivamente na intenção comportamental dos respondentes e foram consideradas importantes para desenvolver uma imagem satisfatória das marcas próprias.

Porém, este investimento pode esbarrar no fator "custo", pois o preço mais baixo praticado nas marcas próprias é conseqüência de uma grande economia de custos e da forma como são comercializadas. O investimento em ações de comunicação é reduzido ou em muitos casos nulo exatamente para reduzir os custos e praticar preços abaixo das marcas nacionais. Desta forma, por um lado o consumidor se queixa da falta de comunicação sobre os produtos, de informações a respeito da qualidade, dos fornecedores e também da falta de criatividade nas embalagens utilizadas e por outro, os varejistas utilizam destes aspectos para reduzir os custos com as marcas próprias e praticarem preços baixos.

Cabe ao varejista avaliar até que ponto esta falta de investimento em ações de comunicação prejudica no crescimento da participação de suas marcas próprias no mercado. Até mesmo porque se pode perceber que os respondentes ainda utilizam a imagem do preço para inferir sobre a qualidade dos produtos.

Outra importante sugestão aos varejistas é que, ao invés de posicionar as marcas próprias como baixo preço, focar em qualidade, entregar valor superior aos clientes e investir em parcerias com fornecedores que mantenham rigorosos padrões de qualidade. Assim, é fundamental o desenvolvimento de padrões de qualidade que permitam aos consumidores encontrarem constantemente o mesmo nível de qualidade das marcas próprias, tanto dentro das categorias quanto entre as categorias de produtos da marca da loja.

Por fim, para minimizar o risco percebido, os varejistas devem oferecer produtos de marcas próprias que possuem os atributos que os consumidores desejam e esperam encontrar nestes produtos; devem desenvolver um padrão de qualidade que os aproxime das marcas nacionais; desenvolverem ações que melhorem a familiaridade com os produtos; investirem nos atributos extrínsecos dos produtos como embalagem, rótulo, preço e outros fatores que os consumidores utilizam para inferir sobre a qualidade e risco que o consumo dos produtos oferece. Para minimizar o risco social, podem desenvolver mensagens nas ações de comunicação que apelem para a construção da imagem de que os consumidores de marcas 
próprias são inteligentes e conscientes da qualidade, contribuindo, então, para amenizar os riscos associados à compra de marcas próprias.

\section{REFERÊNCIAS}

AAKER, David A. Criando e administrando marcas de sucesso. São Paulo: Futura, 2001.

AILAWADI, Kusum L.; NESLIN, Scott A.; GEDENK, Karen. Pursuing the value-conscious consumer: store brands versus national brand promotions. Journal of Marketing, Associação Americana de Marketing (AMA). v. 65, n.1, p. 71-89, jan. 2001.

AJZEN, Icek; FISHBEIN, Martin. Understanding attitudes and predicting social behavior. Upper Saddler: Prentice Hall, 1980.

ALLPORT, Gordon. Attitudes. In: Murchison, C. (Ed.). Handbook of social psychology. Worcest: Clark University Press, 1935. p. 798-844.

ASSOCIAÇÃO BRASILEIRA DE SUPERMERCADOS (ABRAS). Ranking ABRAS 2008. Superhiper, São Paulo, v. 34, n. 385, p. 36-114 abr. 2008.

BLOEMER, Josee; RUYTER, Ko de. On the relationship between store image, store satisfaction and store loyalty. European Journal of Marketing, Bradford, v. 32, n. 5/6, p. 499, 1998.

BORGES, Admir R. Marketing de varejo: as estratégias adotadas pelos supermercados de vizinhança para conquistar e fidelizar clientes. 2001. 155f. Dissertação (Mestrado) Universidade Federal de Santa Catarina, Santa Catarina, 2001.

BURTON, Scot; LICHTENSTEIN, Donald R.; NETEMEYER, Richard G.; GARRETSON, Judith A. A scale for measuring attitude toward private label products and an examination of its psychological and behavioral correlates. Journal of the Academy of Marketing Science, Greenvale, v. 26, n.4, p. 293-306, Fall, 1998.

CARVALHO JUNIOR, César V. O.; BRUNI, Adriano L. Casa de ferreiro, espeto de pau? Uma análise da associação entre a marca de supermercados e os preços praticados no varejo. In: Ângelo, C. F.; Silveira, J. A. (Org.). Varejo competitivo. São Paulo: Saint Paul, 2007. v. 12 , p. 223-245.

CHANIOTAKIS, Ioannis E.; LYMPEROPOULOS, Constantine; SOURELI, Magdalini. Consumer's intention of buying own-label premiun food products. Journal of Product \& Brand Management, MCB University Press, v. 19, n. 5, p. 327-334, 2010 
Uma análise dos principais elementos influenciadores da tomada de decisão de compra de produtos de marca própria de supermercados

COLLINS-DODD, Collen; LINDLEY, Tara. Store brands and retail differentiation: the influence of store image and store brand attitude on store own brand perceptions. Journal of Retailing and Consumer Services, New York, v. 10, p. 345-352, 2003.

COMITÊ ABRAS DE MARCAS PRÓPRIAS (COMPRO). Guia ABRAS de marcas próprias. São Paulo: ABRAS, 2007.

DHAR, Sanjay K.; HOCH, Stephen J. Why store brand penetration varies by retailer. Marketing Science, Linthicum, v. 16, n. 3, p. 208-227, summer, 1997.

DICK, Alan; JAIN, Arun; RICHARDSON, Paul. Correlates of store brand proneness: some empirical observations. Journal of Product \& Brand Management, MCB University Press, v. 4, p. 15-22, 1995.

DICK, Alan; JAIN, Arun; RICHARDSON, Paul. How consumers evaluate store brands. Pricing Strategy \& Practice MCB University Press, v. 5, n. 1, p. 18-24, 1997.

EAGLY, Alice H.; CHAIKEN, Shelly. The psychology of attitudes. Orlando: Hardcoort Brace, 1993.

ENGEL, James F.; BLACKWELL, Roger D.; MINIARD, Paul W. Comportamento do consumidor. São Paulo: LTC, 2000.

EUROMONITOR INTERNATIONAL. Global market information database. Private label in Europe: private label strategies. London, Aug. 1998.

FERRELL, O. C.; HARTLINE, Michael D.; LUCAS Jr., George H.; LUCK, David. Estratégia de marketing. São Paulo: Atlas, 2000.

FISHBEIN, Martin; AJZEN, Icek. Belief, attitude, intention and behaviour: an introduction to theory and research. Reading: Addison-Wesley, 1975.

GRACIOSO, Francisco; NAJJAR, Eduardo R. Desenvolvimento de marcas próprias no Brasil: a experiência do Grupo Pão de Açúcar. Revista da ESPM, São Paulo, v.10, p. 105113. mar.-abr. 2003.

HARCAR, Talha; KARA, Ali; KUCUKEMIROGLU, Orsay. Consumer's percebed value and buying behavior of store brands: and empirical investigation. The Business Review, Cambridge, v. 5, n. 2, p.55-62 Summer 2006. 
Lúcia Aparecida da Silva, Edgard Monforte Merlo \& Marcelo Seido Nagano

HIDALGO, Pedro; MANSSUR, Enrique; OLAVARRIETA, Sérgio; FARÍAS, Pablo. Determinantes de la compra de marcas privadas. Revista de Ciências Sociales, Maracaibo, v. 13, n. 2, p. 205-218, mayo-ago. 2007.

HOCH, Stephen J.; BANERJI, Shumeet. When do private labels succeed? Sloan Management Review, New York, v. 34, n. 4, p. 57, Summer 1993.

HUANG, Ying; HUDDLESTON, Patrícia. Retailer premium own-brands: creating customer loyalty through own-brand products advantage. International Journal of Retail \& Distribution Management, ABI/INFORM Global, v. 37, n. 11, p. 975-992, 2009

LEPSCH, Sérgio Luiz; SILVEIRA, José A. Marcas próprias em supermercados brasileiros. In: SEMINÁRIOS EM ADMINISTRAÇÃO - SEMEAD, 3., 1998, São Paulo. Anais... São Paulo: FEA, 1998. CD-ROM.

LEVY, Michael; WEITZ, Barton A. Administração de varejo. 3. ed. São Paulo: Atlas, 2000.

MACHADO, Marcelo André; MEIRA, Paulo Ricardo S.; COSTA, Filipe C. X.; LARENTIS, Fabiano. Relações de preferência dos consumidores de marcas próprias em supermercados. In: ÂNGELO, C. F.; SILVEIRA, J. A. G. (Org.). Varejo competitivo. São Paulo: Saint-Paul, 2007. v. 12, p. 113-137.

MALHOTRA, Naresh K. Pesquisa de marketing: uma orientação aplicada. Porto Alegre: Bookman, 2006.

MCGOLDRICK, Peter J. Retail marketing. London: McGraw-Hill, 2002.

MIERES, Celina G.; MARTíN, Ana Maria D.; GUTIÉRREZ, Juan A. Antecedents of the difference in perceived risk between store brands and national brands. European Journal of Marketing, Bradford, v. 40, n 1/2, p. 61-82, 2006.

MONTEIRO NETO, Carlos B. Marcas próprias em supermercados: uma estratégia de diferenciação. In: SEMINÁRIOS EM ADMINISTRAÇÃO - SEMEAD, 5., 2001, São Paulo. Anais... São Paulo: FEA, 2001. CD-ROM.

NARASIMHAN, Chakravarthi; WILCOX, Ronald T. Private labels and the channel relationship: a cross-category analysis. Journal of Business, Chicago, v. 71, n. 4, p. 573-600, 1998.

NASCIMENTO, Roberto. Marca própria. Rio de Janeiro: Brasport, 2005. 
Uma análise dos principais elementos influenciadores da tomada de decisão de compra de produtos de marca própria de supermercados

NIELSEN. $16^{\circ}$ Estudo Anual de Marcas Próprias, out. 2010. Disponível em:

$<$ http://br.nielsen.com/news/Pesquisa_marcas_proprias.shtml >. Acesso em: 29 mar. 2011.

PAPPU, Ravi; QUESTER, Pascale. Does customer satisfaction lead to improved brand equity? An empirical examination of two categories of retail brands. The Journal of Product and Brand Management, MCB University Press, v. 15, n. 1, p. 4-14, 2006.

PARENTE, Juracy. Varejo no Brasil: gestão e estratégia. São Paulo: Atlas, 2000.

PEREIRA, Ines. Marcas de supermercado. RAE, São Paulo, v. 41, n.1, 16-27, 2001

RICHARDSON, Alan; DICK, S.; JAIN, K. Extrinsic and intrinsic cue effects on perceptions of store brand quality. The Journal of Marketing, Chicago, v. 58, n. 4, p. 28-36, Oct. 1994.

SAAB, William G. Lopes; GIMENEZ, Luiz Carlos P. Aspectos atuais do varejo de alimentos no mundo e no Brasil. BNDES Setorial, Rio de Janeiro, n. 11, p. 101-122, mar. 2000a.

SANTOS, Sandra C.; CAMPOMAR, Marcos C.; TOLEDO, Geraldo L. Marcas próprias no varejo: evolução, estratégias e desafios. In: SEMINÁRIOS EM ADMINISTRAÇÃO SEMEAD, 8., 2010, São Paulo. Anais... São Paulo: FEA, 2010. CD-ROM

SHANNON, Randall; MANDHACHITARA, Rujirutana. Private-label grocery shopping attitudes and behaviour: s cross-cultural study. Journal of Brand Management, London, v. 12, n. 6, p. 461, Aug. 2005.

SHETH, Jagdish; MITTAL, Banwari; NEWMAN, Bruce I. Comportamento do cliente: indo além do comportamento do consumidor. São Paulo: Atlas, 2001.

SOUZA, Marcos G.; SERRENTINO, Alberto. Multivarejo ${ }^{\text {md: }}$ na próxima economia. São Paulo: Pearson, 2002.

SOUZA, Tereza; QUEIROZ, Tatiana S.; CAMPOS, Domingos F.; VIEIRA, Ricardo S. G. Estratégias de marketing: marcas próprias como um diferencial competitive no setor de supermercados. Revista Brasileira de Gestão de Negócios, São Paulo, v. 11, n. 20, p. 19-37, jan/mar 2009.

TOLEDO, Geraldo L.; GIRALDI, Janaina M. E.; PRADO, Kare P. L. A. Mapa perceptual de marcas próprias: uma investigação das principais marcas de grandes redes de supermercados no Brasil. Revista de Gestão USP, São Paulo, v. 14, n. 4, p. 77-92, 2007. 
UNTERLEIDER, Jorge A. A.; DAMACENA, Cláudio. Estratégia de Desenvolvimento de marcas próprias por supermercados no Brasil. Revista de Administração Mackenzie, v. 7, n. 3, p 63-89, 2006.

VAHIE, Archna; PASWAN, Audhesh. Private label brand image: its relationship with store image and national brand. International Journal of Retail \& Distribution Management, ABI/INFORM Global, v. 34, n.1, p. 67, 2006.

WELLS, William; PRENSKY, David. Consumer behavior. New York: Wiley, 1996. 